\title{
Novel Extravesical Versus Transvesical Technique for Abdominal Repair of Vesicovaginal Fistula
}

\author{
Ibrahem Ismail Samaha, $₫$ Kareem M. Taha, Islam Elbabouly, Maged Ali \\ Department of Urology, Faculty of Human Medicine, Zagazig University, Zagazig, Egypt
}

\section{Abstract}

Objectives To compare the transvesical transabdominal repair of vesicovaginal fistula with novel extravesical transabdominal repair with respect to operative time, blood loss, hospital stay, catheterization time, postoperative lower urinary tract symptoms, urodynamic changes, and recurrence rate.

Methods A prospective randomized controlled study of 94 consecutive female patients who underwent transabdominal vesicovaginal fistula (VVF) repair from March 2013 to March 2018 in our center. The patients had high vesicovaginal fistula that could not be operated on transvaginally: 47 cases were treated with extravesical transabdominal technique, and 47 cases were treated with transvesical transabdominal technique. The primary endpoint is the functional outcome regarding postoperative lower urinary tract symptoms (LUTS); secondary outcomes are early recovery and success rates. The follow-up period was 3 months for reporting and dealing with any complications.

Results There was no significant difference between the groups regarding demographic data. Extravesical repair of VVF had significantly higher $(106.56 \pm 10.46 \mathrm{~min})$ operating time than transvesical repair $(95.08 \pm 7.6 \mathrm{~min}) P<0.001$. There was no significant difference regarding intraoperative blood loss between the extravesical $(365.42 \pm 81.29 \mathrm{~mL})$ and transvesical $(353.12 \pm 73.9 \mathrm{~mL})$ groups; $P=0.44)$. The extravesical group had a significant shorter hospital stay (62.35 \pm 12.25 hours) than the transvesical repair group $(85.07 \pm 12.0$ hours) $P<0.001$. Postoperative storage LUTS 6 weeks assessed by Overactive Bladder Symptom Score was significantly lower for extravesical repair $(1.75 \pm 0.59)$ than for transvesical repair $(6.87 \pm 2.24) P=0.001)$. This was confirmed by urodynamic evaluation. Two patients $(4.2 \%)$ in the transvesical group but none in the extravesical group experienced fistula recurrence.

Conclusions The extravesical transabdominal approach for repair of vesicovaginal fistula is a novel, successful, and versatile technique with reduced hospital stay, reduced postoperative LUTS and possibly fewer recurrences than the transvesical technique, and should be considered for all VVF requiring abdominal repair.

\section{Introduction}

Vesicovaginal fistula (VVF) is an abnormal communication between the bladder and the vagina resulting in continuous leakage of urine[1]. VVF remains a devastating disease with social stigma and psychological strain on patients, as well as physical repercussions[2]. Etiology of VVF includes obstetric injury, gynecological and pelvic surgeries, radiation therapy, inflammation, and malignancy, but the obstetric complications with prolonged labour remain the predominant cause in the developing countries. Inadvertent bladder injury during hysterectomy is the most common cause in developed countries with reported rates of $0.3 \%$ to $2 \%$ after simple hysterectomy and $10 \%$ after radical hysterectomy $[3,4]$.

\section{Key Words}

Vesicovaginal fistula, transvesical repair, lower urinary tract symptoms, overactive bladder symptoms score, urodynamic study

\section{Competing Interests}

None declared.

\section{Article Information}

Received on September 17, 2020

Accepted on January 4, 2021

Soc Int Urol J.2021;2(2):113-119

DOI: https://10.48083/TVYU2515 
Fistula occurs when devascularized tissue is sloughed. Leakage of urine through this focus of erosion leads to the formation of a tract through fibrotic tissue that connects the urinary tract to the bladder. This fistula is usually recognized 2 weeks after the trauma[5].

The O'Conor transvesical technique was performed via laparotomy for more than 30 years before the first laparoscopic case was published in 1994[6]. It was not until 1998 that von Theobold described the first laparoscopic extravesical VVF repair. Von Theobold describes a simple dissection of the bladder away from the vagina and a single-layer bladder closure, noting "closure of the vagina was not necessary" coupled with an omental J flap[7].

The extravesical approach is not a modification of the O'Conor technique, as a cystotomy is not required to identify the fistula, but it still uses the basic principles of fistula repair as cited by Couvelaire in the 1950s[8].

\section{FIGURE 1.}

A

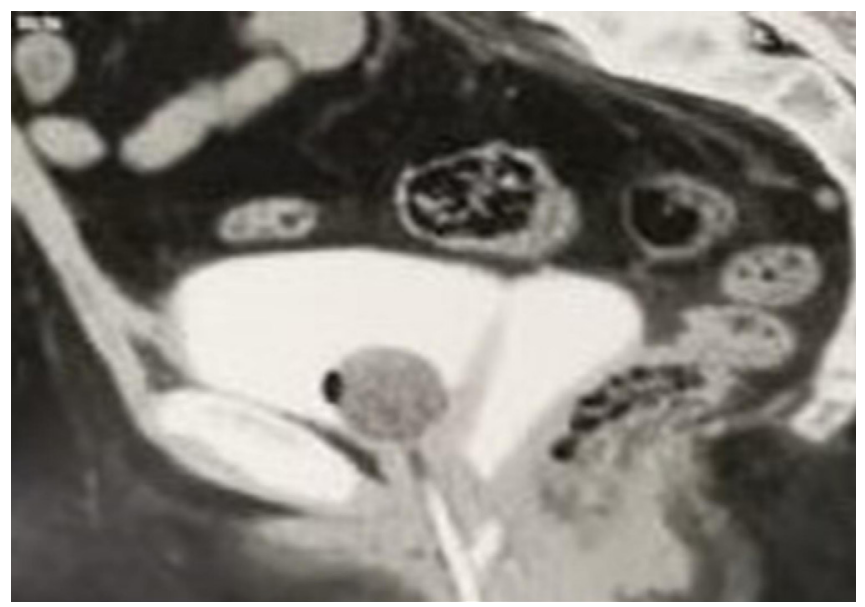

Sagittal section of CT cystogram
The extravesical approach, first described by Von Dittel in 1893 [9], focuses on targeted dissection, avoiding cystotomy, and preferentially dissecting to the fistulous tract via the vesicovaginal plane. The superiority of either the transvesical or the extravesical approach has not been established in the literature and at the time of writing, no study has compared the 2 techniques[10].

The aim of this study was to compare the effectiveness of the extravesical technique of transabdominal repair with the transvesical technique of transabdominal repair for vesicovaginal fistula with respect to operative time, blood loss, length of hospital stays, urethral catheter time, postoperative lower urinary tract symptoms and recurrence rate. The primary endpoint is the functional outcome regarding postoperative lower urinary tract symptoms (LUTS); secondary outcomes are early recovery and success rates. The follow-up period was 3 months for reporting and dealing with any complications.

\section{B}

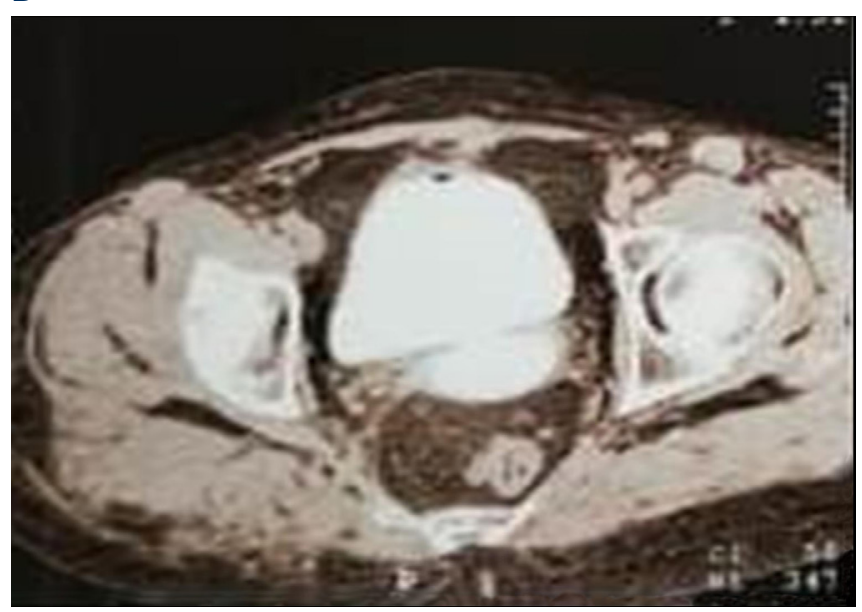

Axial section

C

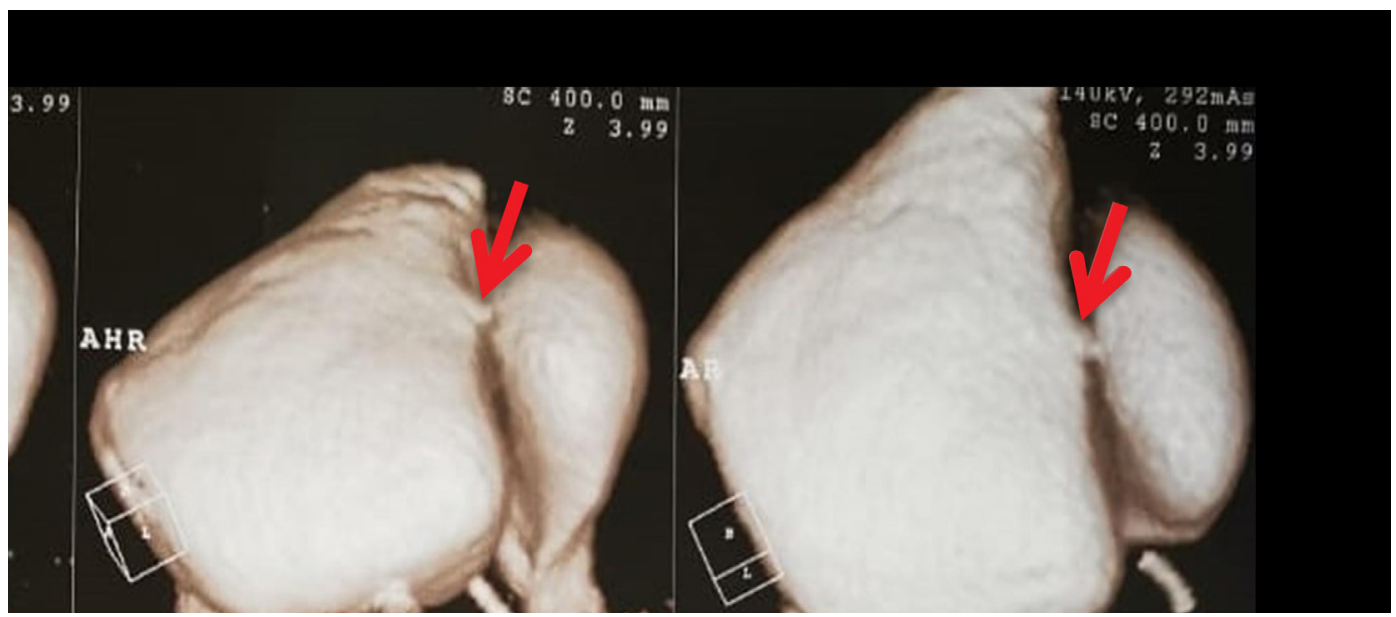

3D Format: red arrow shows the high VVF and opacification of the vagina with contrast 


\section{Materials and Methods}

We undertook a prospective randomized controlled study with 94 consecutive female patients who underwent transabdominal vesicovaginal repair from March 2013 to March 2018 in our center (Zagazig University Hospital). Patients with fistulas close to the ureteric orifice and high fistulas that could not be accessed through the vagina, as well as those with previous recurrent vaginal surgeries that precluded vaginal repair were enrolled in this study and underwent abdominal repair. Patient consent and institutional review board approval were obtained.

Between 2013 and 2018, 94 consecutive female patients with high vesicovaginal fistula or previous vaginal surgery that precluded transvaginal fistula repair were randomized to fistula repair by an extravesical transabdominal technique $(n=47)$ or by a transvesical transabdominal technique $(\mathrm{n}=47)$ at our center. Preoperative patient evaluation included history, physical examination (local vaginal examination, inspection with speculum, dye test), and CT cystogram (Figure 1). Informed consent was obtained from all patients prior to surgery, and institutional review board approval was granted.

\section{Operation}

Diagnostic cystoscopy was done first to identify the fistula tract with stent insertion inside it, A vaginal pack was then inserted, and a vertical lower abdominal midline incision was made for better exposure and easy access for omental flap formation.

All VVF in our series were repaired 3 months after the initial trauma to allow edema and inflammation to subside and allow better tissue handling and healing. The fundamental surgical principles for repair (adequate exposure, tension-free approximation of the fistula edges, non-overlapping suture lines, good hemostasis, watertight closure, and adequate postoperative bladder drainage) were achieved.

\section{Transvesical Approach}

This is based on the technique described by O'Conor and Sokol. After exposure of the pelvic structures, mobilization of bladder was obtained[11]. A cystotomy (4 to $5 \mathrm{~cm}$ ) along the sagittal plane near the dome was done. The incision was then extended down to the site of the fistulous tract. Both ureteral orifices were identified before dissection along the tract course and a fullthickness excision of the tract and the devascularized edges, followed by double-layered closure of the bladder and vaginal defects with omental flap interposition. The bladder was filled with saline to ensure watertight closure. A urethral catheter remained in place for 2 weeks postoperatively.

\section{Extravesical Approach}

This approach focuses on targeted dissection with preferential dissection to the fistulous tract via the vesicovaginal plane, thereby avoiding cystotomy. The fistulous tract was excised. A multilayered closure, with non-overlapping suture lines was done. The vaginal defect was closed in a double layer, using interrupted 2-0 absorbable sutures. The bladder defect was repaired in 2 layers with continuous suturing using a 2-0 absorbable suture as shown in Figure 2. Retrograde filling of the bladder was done to ensure a watertight seal. An omental flap was used as a tissue interposition between bladder and vagina. The urethral catheter remained in place for 5 days postoperatively.

In all patients after both approaches lower urinary tract symptoms were evaluated after 6 weeks with the Overactive Bladder Symptom Score (OABSS) by filling cystometry.

\section{Results}

\section{Clinical and Pathologic Characteristics}

Ninety-four patients with high vesicovaginal fistula underwent transabdominal repair. Patients were randomly assigned to receive transvesical

\section{FIGURE 2.}
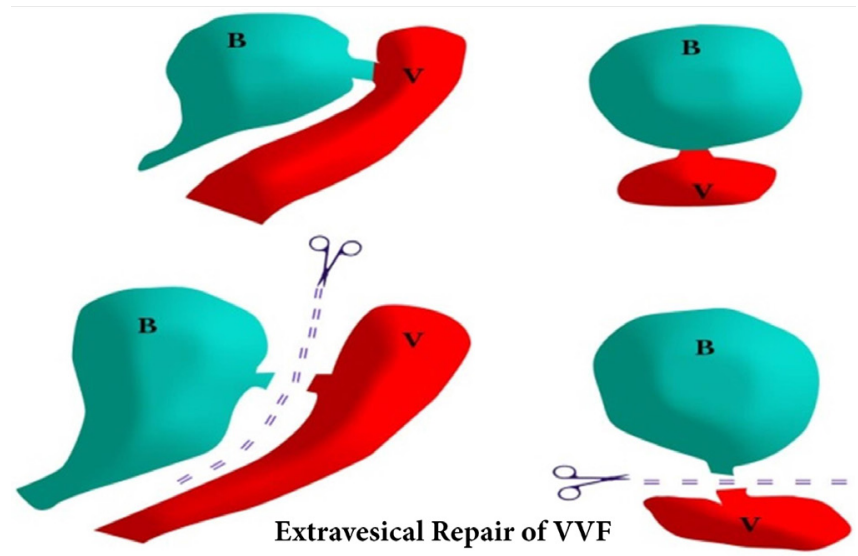

Extravesical Repair of VVF

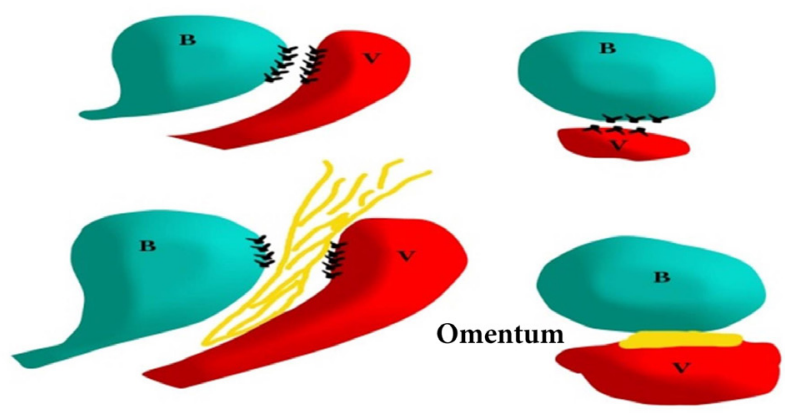

Steps of extravesical repair of VVF

$B$ - Bladder

V - Vagina with the yellow omental flap in between 
transabdominal repair (47 patients) or extravesical transabdominal VVF repair (47 patients). There was no significant difference between the groups with respect to age, body mass index (Table 1), or cause of vesicovaginal fistula (Table 2).

\section{Clinical Outcomes}

The operative time was greater for the extravesical approach $(106.56 \pm 10.46 \mathrm{~min})$ than the transvesical approach $(95.08 \pm 7.6 \mathrm{~min})(P<0.001)$ due to the more delicate dissection to mobilize the posterior bladder away from the vagina without cystotomy. Intraoperative blood loss was not significantly different for the extravesical repair group $(365.42 \pm 81.29 \mathrm{~mL})$ and for the transvesical repair group $(353.12 \pm 73.9 \mathrm{~mL} ; P=0.44)$. However, the extravesical group had a significantly

\section{TABLE 1.}

Age and BMI distribution

\begin{tabular}{|c|c|c|c|c|}
\hline & Transvesical & Extravesical & $\mathbf{t}$ & $\boldsymbol{P}$ \\
\hline & $\begin{array}{c}n=47 \\
\text { (Mean } \pm S D)\end{array}$ & $\begin{array}{c}n=47 \\
\text { (Mean } \pm S D)\end{array}$ & & \\
\hline Age & $45.16 \pm 10.6$ & $47.01 \pm 11.26$ & -1.645 & 0.074 \\
\hline BMI & $29.75 \pm 3.37$ & $30.0 \pm 3.62$ & -0.535 & 0.584 \\
\hline
\end{tabular}

No significant difference between both groups for demographic data shorter hospital stay $(62.35 \pm 12.25$ hours $)$ than the transvesical repair group $(85.07 \pm 12.0$ hours $)(P<0.001)$.

We also compared the functional outcomes for both techniques of repair in terms of storage LUTS, using the OABSS 6 weeks postoperatively. Extravesical repair of VVF caused significantly lower postoperative OABSS $(1.75 \pm 0.59)$ compared with transvesical repair (6.87 \pm 2.24$) P=0.001$ (Table 3). This was confirmed objectively by urodynamic evaluation (Table 5 ), which revealed detrusor overactivity in 14 patients (31.1\%) in the transvesical group and 5 patients $(10.6 \%)$ in the extravesical group $(P=0.002)$. Detrusor overactivity incontinence was observed in 7 patients $(15.5 \%)$ in the transvesical group and in 2 patients $(4.2 \%)$ in the extravesical group $(P=0.018)$. This was managed with antimuscarinic drug. Post repair stress urinary incontinence was observed in 3 patients $(6.6 \%)$ in the transvesical group and 1 patient $(2.1 \%)$ in the extravesical group $(P=0.15)$. This was managed conservatively.

Fistula recurrence was observed in 2 patients (4.2\%) within 4 weeks in the transvesical group and none in the extravesical group $(P=0.11)$ (Table 3$)$.

\section{Discussion}

Vesicovaginal fistula is one of the most distressing complications of obstetric and gynecologic procedures. It has a negative impact on life with important medicolegal implications. Obstetric VVFs remain a major medical problem in many low-resource countries with a low standard of antenatal and obstetric care[12].

TABLE 2.

Causes of vesicovaginal fistula

\begin{tabular}{|c|c|c|c|c|c|}
\hline \multirow{2}{*}{ Cause } & \multicolumn{2}{|c|}{ Group } & \multirow{2}{*}{$\begin{array}{l}\text { Total } \\
n(\%)\end{array}$} & \multirow{2}{*}{$x^{2}$} & \multirow{2}{*}{$P$} \\
\hline & $\begin{array}{c}\text { Transvesical } \\
n(\%)\end{array}$ & $\begin{array}{c}\text { Extravesical } \\
n(\%)\end{array}$ & & & \\
\hline Cystocele repair & $7(14.8)$ & $8(17)$ & 15(19.2) & 0.29 & 0.59 \\
\hline Hysterectomy & $21(44.6)$ & $23(49)$ & $44(53.6)$ & 0.26 & 0.61 \\
\hline Obstructed labour & $13(27.6)$ & $10(21.2)$ & $23(20.5)$ & 0.75 & 0.38 \\
\hline PVS & $1(2.1)$ & $2(4.2)$ & $3(0.9)$ & 0.72 & 0.39 \\
\hline TVT & $5(10.6)$ & $4(8.5)$ & $9(5.8)$ & 0.15 & 0.69 \\
\hline Total & 47 & 47 & 94 & & \\
\hline
\end{tabular}




\section{TABLE 3.}

Clinical outcomes

\begin{tabular}{|c|c|c|c|c|}
\hline & $\begin{array}{c}\text { Transvesical } \\
\mathbf{n = 4 7}\end{array}$ & $\begin{array}{c}\text { Extravesical } \\
\mathbf{n = 4 7}\end{array}$ & $\mathbf{t}$ & $\mathbf{P}$ \\
\hline $\begin{array}{c}\text { Operation time } \\
\text { (min) }\end{array}$ & $95.08 \pm 7.6$ & $106.56 \pm 10.46$ & -8.121 & 0.001 \\
\hline $\begin{array}{c}\text { Blood loss } \\
\text { (mL) }\end{array}$ & $353.12 \pm 73.9$ & $365.42 \pm 81.29$ & -0.684 & 0.44 \\
\hline $\begin{array}{c}\text { Length of } \\
\text { hospital stay } \\
\text { (hour) }\end{array}$ & $85.07 \pm 12.0$ & $62.35 \pm 12.25$ & 14.015 & $<0.001$ \\
\hline $\begin{array}{c}\text { Postoperative } \\
\text { OABSS }\end{array}$ & $6.87 \pm 2.24$ & $1.75 \pm 0.59$ & 20.988 & 0.001 \\
\hline & $2(4.2 \%)$ & 0 & Fisher & 0.11 \\
\hline \begin{tabular}{c} 
Recurrence \\
\hline
\end{tabular} & & & 2.41 & \\
\hline
\end{tabular}

TABLE 4.

Causes of VVF in different studies

\begin{tabular}{|l|c|c|c|c|}
\hline Causes & $\begin{array}{c}\text { Present } \\
\text { study }\end{array}$ & $\begin{array}{c}\text { Kapoor } \\
\text { et al., } \\
\mathbf{2 0 0 7}\end{array}$ & $\begin{array}{r}\text { Roy } \\
\text { et al., } \\
\mathbf{2 0 0 6}\end{array}$ & $\begin{array}{r}\text { Kam } \\
\text { et al., } \\
\mathbf{2 0 0 8}\end{array}$ \\
\hline$\sqrt{ }$ Obstetric & 44 & 60 & 22 & 25 \\
\hline $\begin{array}{l}\text { Gynecological } \\
\text { V Other causes } \\
\text { (PoP repair, continence } \\
\text { surgeries) }\end{array}$ & 23 & 40 & 74 & 70 \\
\hline
\end{tabular}

Transabdominal repair is the preferred approach when the fistula is high on the posterior bladder or the fistula is complex, or if the vaginal anatomy precludes adequate surgical exposure of the defect (retracted defect or narrow vagina), or the fistula is closely related to the distal ureters[13].

In the present study $53.6 \%$ fistulas were secondary to gynecological procedures (hysterectomy) and 20.5\% resulted from obstetric problems, which reflects the findings of the study by Kapoor et al.[14]. In other series, however, VVF was reported as predominantly secondary to gynecological causes, as shown in Table 4.

We wished to evaluate the outcomes of extravesical VVF repair and compare them with the classical transvesical technique because we believed that avoiding cystostomy could reduce postoperative drawbacks in the form of long hospital stay, long catheterization time, and high incidence of storage LUTS.

Dolan et al. report that $16.1 \%$ of patients experience stress urinary incontinence after fistula repair[15]. This results from defunctionalization of the detrusor muscle because of prolonged VVF exposure[8]. The substantial loss of bladder tissue from scarring leads to a smaller functional bladder capacity. The bladder then becomes stiff and non-compliant leading to stress incontinence or de novo urge incontinence. Vaginal scarring and shortening of the vagina impair physiologic urethral function and prevent adequate urethral coaptation[16]. In a study of obstetric fistula in Ethiopia, where urodynamic investigation was undertaken after repair, $55 \%$ of patients were incontinent despite successful closure of their fistula; stress urinary incontinence was most commonly identified abnormality[17]. Another study demonstrated stress urinary incontinence in $47 \%$ of women prior to repair in a series of largely surgical fistulae in the United Kingdom. Although in only 3\% did this persist after repair, these findings are more common in obstetric fistula. Detrusor overactivity was found in $40 \%$ at presentation and persisted in half of these at follow-up [18].

We believe that the extravesical technique is a more successful, less invasive, and less traumatic repair with a lower incidence of detrusor overactivity. The key difference is the targeted dissection of the VVF site and the layered-closure technique discussed here. In contrast, the bivalving of the bladder required with the traditional transvesical approach increases the size of the bladder defect, which may be responsible for the varied success rate (70\% to $97 \%)$. This rationale is supported by fistula experts who have stated that there is a greater chance of surgical failure with larger fistulas[16] and have advised minimizing the size of the cystotomy $(<2 \mathrm{~cm})$ during an O'Conor transvesical repair. Others

\section{TABLE 5.}

Urodynamic evaluation

\begin{tabular}{|c|c|c|c|}
\hline Procedure & $\begin{array}{c}\text { Detrusor } \\
\text { overactivity } \\
\mathbf{n}(\%)\end{array}$ & $\begin{array}{c}\text { Detrusor } \\
\text { overactivity } \\
\text { incontinence } \\
\mathbf{n}(\%)\end{array}$ & $\begin{array}{c}\text { Stress } \\
\text { urinary } \\
\text { incontinence } \\
\mathbf{n ( \% )}\end{array}$ \\
\hline Transvesical (45) & $14(31.1)$ & $7(15.5)$ & $3(6.6)$ \\
\hline Extravesical (47) & $5(10.6)$ & $2(4.2)$ & $1(2.1)$ \\
\hline$P$ & 0.002 & 0.018 & 0.15 \\
\hline
\end{tabular}


have reported great success using the nonbivalving extravesical layered-closure technique with and without omental flaps[20,21].

It was clear in this series that the success rate with the transvesical approach was 95\%, with failure in 2 cases, compared with extravesical repair, which had a success rate of $100 \%$.

We attribute the high success rate to meticulous and site-specific dissection as well as a triple-layer closure, which included a double-layered bladder closure and single vaginal wall closure, as supported by Sokol et al.[22], as well as aggressive testing of the bladder's suture line. In a study using a canine model, Sokol et al. suggest that a double-layer closure of cystotomy is superior to a single-layer closure and may prevent fistula. Also good tissue approximation and watertight closure are fundamentals for successful VVF repair. To determine whether a "watertight seal" had been achieved, we undertook retrograde filling of the bladder; we then sutured any leaking points in the suture line. However, the technique to determine a "watertight seal" has never been adequately defined and lacks consistency, as suggested in the literature[23].

In this series we fixed omental flap as interpositioning layer in all cases, whether transvesical or extravesical, to promote healing and better lymphatic drainage, although the use of interposition flaps in non-irradiated patients has been questioned[24,25].

In a recent retrospective review of 49 patients without malignancy or a history of radiation therapy, the primary surgeon determined that transvaginal repair of benign recurrent VVFs without tissue interposition can be as successful as primary repairs without tissue interposition[26]. An interposition graft for VVFs functions as a barrier and introduces vascularity and, theoretically, lymphatics to improve tissue growth and maturation.

Decisions about approach, technique, interposition grafts, and layers of closure are still debated and must be based on the individual surgeon's experience and comfort level. Thus, a surgeon's decision to approach a VVF vaginally, laparoscopically, or via laparotomy is based primarily on the individual's skill, comfort, and ability.

To our knowledge, this study is the first to compare and discuss the outcomes of transabdominal VVF and transvesical repair. We believed that extravesical repair of VVF had better outcomes than the traditional transvesical repair, and this randomized controlled trial provided support for that view. No matter which approach decided upon, we believe that the most important aspects of VVF repair remain adequate dissection, a watertight seal, and good postoperative bladder drainage.

\section{Conclusions}

The extravesical abdominal approach for repair of vesicovaginal fistula is associated with significantly reduced hospital stay, significantly reduced postoperative overactive bladder symptoms, and a reduced recurrence rate compared with the transvesical approach. We recommend this technique for closure of VVF that must be repaired abdominally. 


\section{References}

1. Zacharin RF. A history of obstetric vesicovaginal fistula. Aust N Z J Surg.2000;70(12):851-854.

2. Alio AP, Merrell L, Roxburgh K, Clayton HB, Marty PJ, Bomboka L, et al. The psychosocial impact of vesico-vaginal fistula in Niger. Arch Gynecol Obstet.2011; 284(2):371-378.

3. Eilber KS, Kavaler E, Rodriguez LV, Rosenblum N, Raz S. Ten-year experience with transvaginal vesicovaginal fistula repair using tissue interposition. J Urol.2003;169(3):1033-1036.

4. Duong TH, Taylor DP, Meeks GR. A multicentre study of vesicovaginal fistula following incidental cystotomy during benign hysterectomies. Int Urogynecol J.2011;22(8):975-979.

5. Malik MA, Sohail M, Malik MT, Khalid N, Akram A. Changing trends in the etiology and management of vesicovaginal fistula. Int J Urol.2018;25(1):25-29.

6. Nezhat CH, Nezhat F, Nezhat C, Rottenber H. Laparoscopic repair of a vesicovaginal fistula: a case report. Obstet Gynecol.1994;83(5Pt2):899-901.

7. Von Theobold P, Hamel P, Febrarro W. Laparoscopic repair of a vesicovaginal fistula using an omental $\mathrm{J}$ flap. Br J Obstet Gynaecol.1998;105(11):1216-1218.doi:10.1111/j.1471-0528.1998. tb09980.x.

8. Couvelaire R. Reflections on a personal statistic of 136 vesicovaginal fistulas. J Urol Med Chir.1953;59:150-160.

9. Von Dittel L. Abdominale Blasenscheidenfistel-operation. Wein Klin Wochenschr.1893;6:449-452.

10. Miklos JR, Moore RD, Chinthakanan 0. Laparoscopic and roboticassisted vesicovaginal fistula repair: a systematic review of the literature. J Minim Invasive Gynecol.2015;22(5):727-736.

11. O'Conor VJ, Sokol JK. Vesicovaginal fistula from the standpoint of the urologist. J Urol.1951 Oct;66(4):579-585. doi: 10.1016/ s0022-5347(17)74381-9.

12. Hadley HR. Vesicovaginal fistula. Curr Urol Rep.2002;3(5):401-407.

13. Romics I, Kelemen Z, Fazakas Z. The diagnosis and management of vesicovaginal fistulae. BJU Int.2002;89(7):764-766.

14. Kapoor R, Ansari MS, Singh P, Gupta P, Khurana N, Mandhani A, et al. Management of vesicovaginal fistula: an experience of 52 cases with a rationalized algorithm for choosing the transvaginal or transabdominal approach. Indian J Urol.2007 Oct;23(4):372.
15. Dolan LM, Dixon WE, Hilton P. Urinary symptoms and quality of life in women following urogenital fistula repair: a long-term follow-up study. BJOG.2008;115:1570e4.

16. Ayed M, El Atat R, Hassine LB, Sfaxi M, Chebil M, Zmerili S. Prognostic factors of recurrence after vesicovaginal fistula repair. Int J Urol.2006;(4):345-349. D0I: 10.1111/j.1442-2042.2006.01308.x

17. Murray C, Goh JT, Fynes M, Carey MP. Urinary and faecal incontinence following delayed primary repair of obstetric genital fistula. BJOG.2002;109:828-832.

18. Hilton P. The urodynamic findings in patients with urogenital fistulae. Br J Urol.1998;81:539-42.

19. Rizvi SJ, Gupta R, Patel S, Trivedi A, Trivedi P, Modi P. Modified laparoscopic abdominal vesico-vaginal fistula repair-"Mini-0'Conor" vesicotomy. J Laparoendosc Adv Surg Tech.2010;20(1):13-15.

20. Das Mahapatra P, Bhattacharyya P. Laparoscopic intraperitoneal repair of high-up urinary bladder fistula: a review of 12 cases. Int Urogynecol J.2007;18:635-639.

21. Abdel-Karim AM, Mousa A, Hasouna M, Elsalmy S. Laparoscopic transperitoneal extravesical repair of vesicovaginal fistula. Int Urogynecol J.2011;22(6):693-697.

22. Sokol Al, Paraiso MF, Cogan SL, Bedaiwy MA, Escobar PF, Barber MD. Prevention of vesicovaginal fistulas after laparoscopic hysterectomy with electrosurgical cytostomy in female mongrel dogs. Am J Obstet Gynecol.2004;190:628-633.

23. Shah SJ. Laparoscopic transabdominal transvesical vesicovaginal fistula repair. J Endourol.2009;23(7):1135-1137.

24. Miklos JR, Moore RD. Laparoscopic transperitoneal extravesical approach to vesicovaginal fistula repair without omental flap: a novel technique. Int Urogynecol J.2014;26(3):441-446.

25. Kohli N, Miklos JR. Meeting the challenge of the vesicovaginal fistula repair: conservative and surgical measures. $O B G$ Manag.2003;8:16-27.

26. Pshak R, Nikolavsky D, Terlecki R, Flynn BJ. Is tissue interposition always necessary in transvaginal repair of benign, recurrent vesicovaginal fistula. Urology.2013;82(3):707-712. doi: 10.1016/j. urology.2013.03.076. 